\title{
What's Left Is Closer to Right
}

\author{
A Response to Keating \\ JAMES P. BYRNES \\ University of Michigan
}

\begin{abstract}
The present paper attempts to respond to criticisms made by Keating (1988, Developmental Review, 8, 376-384) regarding the present author's earlier paper which described a recasted model of formal operations (Byrnes, 1988, Developmental Review, 8, 66-87). This earlier paper made a distinction between conceptual and procedural knowledge at the level of formal operations, and presented evidence supporting this recasted model. Keating (1988) argues that the recasted model fails to capture what Piaget originally intended, that it fails to incorporate a procedural knowledge component, and that there is some question as to what would constitute empirical support for the model. The present paper discusses each of these criticisms and others in turn, and clarifies earlier arguments. 1988 Academic Press, Inc.
\end{abstract}

In a previous paper (Byrnes, 1988), I proposed a reformulation of the formal operations model originally described by Inhelder and Piaget (1958) and revised in Piaget (1972a). In that paper, I argued that reasoning domains consist of two components: "knowing that" knowledge and "knowing how" knowledge (Ryle, 1971). The former is analogous to what has been called conceptual knowledge (Hiebert \& LeFevre, 1987) or declarative knowledge (Mandler, 1983). It consists of networks of the core concepts for a given domain. "Knowing how" knowledge is simply a representation of the steps one should take in order to solve a problem. It has been more recently referred to as procedural knowledge (Anderson, 1976; Mandler, 1983). In the domain of physics, for example, "knowing that" (conceptual) knowledge would consist of an understanding of the relation between the core concepts "force" and "mass." "Knowing how" (procedural) knowledge, on the other hand, would consist of knowing how to, for example, solve introductory physics text problems using formulas and the like. Such forms of knowledge are obviously distinct as indicated by the ability of students to correctly solve problems using rote procedures, while at the same time failing to comprehend the core concepts and their interrelations (sec Carey, 1985, or Chi, Glaser, \& Rees, 1982).

In my paper, I drew a distinction between conceptual and procedural

Requests for reprints should be addressed to James Byrnes at the Department of Developmental Psychology, University of Michigan, Ann Arbor, MI 48109. 
knowledge with regards to formal operational thought. I argued that the 16 binary operations represent a formalized model of conceptual knowledge that includes the propositional concepts of implication, disjunction, equivalence, and conjunction, as well as their interrelations. Piaget also discussed formal operational schemata such as isolation of variables, combinations, etc., which I categorized as instances of procedural knowledge. My primary point was that too much emphasis has been placed on the formal operational schemata in the American literature, and too little placed on the propositional concepts available to a formal operational subject. I argued that this was due to the fact that the only translated work on formal operations was Inhelder and Piaget (1958) which, also placed a lot of emphasis on the schemata. Moreover, these authors failed to keep conceptual and procedural knowledge distinct in this work by using the formalism for the conceptual knowledge to characterize procedural knowledge. In my reformulation, I attempted to make the distinction clear. Moreover, I used Lakatos' (1971) characterization of theories to propose that the essential, nondeletable features of the theory of formal operations are (a) operations on operations, (b) propositional representation, (c) all possible combinations, and (d) hypothetical thinking. I discussed conceptual knowledge in the context of these features. I then attempted to show how these features have achieved a much higher level of empirical support than was found for the schemata.

Keating in his recent commentary on my paper (Keating, 1988) argues, in general, that my reformulation fails to capture what Piaget originally intended, that my view is regressive rather than progressive, and that there is a question of validity (in the methodological sense) in my discussion of what constitutes empirical support for my model. He makes the following specific criticisms that I would like to discuss in turn: (a) It is mistaken to say that the structural organization of the 16 binary operations is what the theory really is about and that the know-how aspects of the theory can be deleted without harm to the theory. (b) My paper dismisses the tension between closed structures and open systems. (c) My model idealizes a propositional logic as an end goal and isolates structure from function. (d) Psychometricians would be troubled by the claim that propositional reasoning tasks are "direct" tests of formal operations. (e) People's actual performance on Inhelder and Piaget's (1958) tasks is not irrelevant. (f) My paper omitted Piaget's (1972b) important paper regarding content effects. (g) My model ignores factors such as content knowledge. (h) Byrnes and Overton's (1986) data are not supportive of the new model. (i) What is left is a decontextualized mirage of the mind.

With regards to criticism a, I can simply say that I do not believe that the "knowing how" aspects can be deleted from the theory. My point was 
that conceptual and procedural knowledge are co-equals and that not enough attention has been given to the former. However, since I mistakenly failed to include procedural knowledge as a core feature in my earlier paper, it is easy to see why Keating makes this criticism. I concede that procedural knowledge should be added as an additional feature. However, I agree with Siegler (1986) that it is erroneous to believe that all subjects will correctly solve a problem using the same procedure or strategy. Particularly with complex problems, there are often multiple paths to the same correct answer (though some are more effective than others). Hence, it is possible that someone who fails to employ the correct formal operational strategy will be misclassified as nonformal. For example, with a combinations task, one subject may generate the following combinations from the letters $A B C D$ : $A, B, C, D, A B, A C, A D, B C, B D, C D, A B C$, $A B D, B C D, A B C D$. Note the systematicity of this solution. Another subject likewise "knows" (in the conceptual knowledge sense) that there are combinations of one, two, three, and four letters, yet was never taught or discovered a system. He is likely to generate: $A B, A, C D, A B D, A B C D$, etc. The former is labeled formal operational because she generated all the combinations, and the latter is labeled nonformal because he did not. Hence, a deficiency in procedural knowledge is overgeneralized to conceptual knowledge as well. It is in this sense that I argued in my earlier paper that tests of schemata are indirect assessments of conceptual knowledge. This account explains why it is relatively easy to elicit formal operations in adolescents with minimal feedback as Stone and Day (1980) describe. What is really taught with feedback is a more effective strategy that subjects understand as such because they have necessary conceptual knowledge. What information-processing theorists and functionalists fail to realize is that there is something more to training than the acquisition of procedures, i.e., conceptual knowledge.

In regard to criticism b, I do not dismiss the tension between open and closed systems. Rather, I make a distinction between how knowledge is organized in the mind and the theorist's model of that organization. Consider the following progression in a structuralist's theorizing about reasoning. He or she observes and records a subject say on separate occasions: (1) "If it's past 4 o'clock, she's home. [finds clock] It's 4:15. She's home. (2) "If today's the 15th, my paper is due. [asks friend] Today's the 15 th? Oh no, my paper is due!' Next the theorist detects a formal similarity in these arguments and attempts to summarize them with a formalism: They all have the form "If $p$ then $q$ : $p$, therefore $q$ ". The theorist uses this schema as a model of the actual thought processes. Up to this point he or she has not erred. However, as is usually the case, this structuralist makes the fallacious assumption that this model or formalism 
actually exists in the subject's mind as an abstract, formal entity waiting to become filled in with content. In this way a logical formalism becomes reified and idealized in Keating's sense.

The problem here is not with the claim that there are inferences that have the same structure in the mind, but, rather, with the claim that the formalism exists in the mind. A further problem arises when the structuralist attempts to prove the internal cohension of this model to the scientific or philosophical community. As Godel's proof showed, the only way for one to prove the internal consistency of one's model or system is by appealing to the next more powerful system (see Nagel \& Newman, 1958). Additionally, immediately as one posits a formal model as a theoretical description, one has to place constraints on the kinds of contents which can enter this system (see Chomsky, 1965, pp. 75-79, for example, on semantic constraints on synactic rewrite rules). These limits of formalization have always led to the rejection of a structuralist approach (see, for example, Faulconer \& Williams, 1985, on the value of the hermeneutic over structuralist approaches).

Keating is correct in his belief that Piaget recognized the limits of formalization. Piaget (1962) had the following to say regarding the relation between formalized logics and natural thought:

it is important to have all efforts directed towards the relations between these formalized logics and the corresponding non-formalized forms of thought. These latter forms of thought, called "naive theories" by logicians of the trade, concern natural thought, but of a very superior level to that which concerns us in this work [i.e., nonspecialized ordinary thought], whereas the contemporary formalized logics have essentially the goal of furnishing a foundation for natural mathematical thought. . . . But however elaborated this natural thought of a superior level may be, as opposed to ordinary thought, it is still the case that logical formalisms have failed to structure thought completely and coherently, in other words, there are limits to formalization. . . But the central idea that J. B. Grize defends is without doubt that the limits of formalisms are an index of their efficacy and not of their weakness, once the relations between formalization and natural thought are made precise. But the reason why a formal model does not recover everything which is natural is because, on the one hand, one only formalizes by abstracting from the given data, and, on the other, because a formalism does not constitute a stable state of immutable frontiers, but, on the contrary, represents an activity of formalization. Certainly the development of natural thought does not proceed by additive accumulations, but in a form of an organic growth. A formalization, however, is atemporal. As a result . . . contradictions play a positive role in the evolution of natural thought because they contribute to advancements, whereas in a formalism, contradictions are to be avoided. But it nonetheless remains that rough drafts, that are always made cleaner through formalization, are observed in the successive stages of natural thought, of the sort that, on the whole, there never exists a purely naive state nor a pure formalization. (pp. 4-6)

Piaget refers in the course of this discussion to papers by Ladriere (1967) and Apostel (1967), who summarize the limits of formalization 
presented by Godel, Church, Turing, and others. He also remarked that there will always be a lack of fit between formalisms and thought because the former are changed and developed by theorists in a linear fashion, whereas natural thought progresses through dialectical cycles. It is my contention that he gave up the method of using formalisms based on these arguments, but remained a structuralist. Montangero (1985, p. 33) cites a discussion with Piaget precisely on this point. Regardless, what all these authors refer to is a defect in the process of formalization or modeling, not one in the claim that adolescents acquire concepts of implication, disjunction, etc. Since I do not believe that adolescents have free-floating formalisms in their minds, but, rather, actual content domains organized in the form of implication, disjunction, etc., I am not troubled by the issues of the limits of formalization. I agree with Keating that where most structuralists go wrong is in reifying the model and attributing it to the subject's mind.

Regarding criticism c, I do not see how my depiction isolates structure from function. I attempted only to isolate the organizational aspect of formal operations in order to describe its importance. By omitting a discussion of process in my paper, I do not imply that process is unimportant. Rather, one must distinguish between organization (structure) and organizing (process). Piaget argued that knowledge is always characterized by a certain organization at a certain level of abstraction away from action or perception. He formalized these organizations at various levels by calling them structures. These structures represent frames which are imposed on reality in order to organize information for any given context, i.e., to construct meaning. He called successful organizing assimilation. The organization of knowledge 1 described in my paper represents cognitive structures which the adolescent and adult use as a frame when organizing/assimilating information.

With respect to criticism d, it should be noted that I consider propositional reasoning tasks to be more direct tests of formal operational conceptual knowledge than the standard tasks which measure schemata or procedural knowledge (see also my comments to criticism a above). I by no means claim that the former tasks are "direct" measures, as if the tasks represent entirely valid (in the psychometric sense) operational definitions of formal operational thought. My claim is simply that they are much better measures of conceptual knowledge than standard tasks. Obviously one could devise many other tasks to determine the nature of the organization at the formal operations level (e.g., Carey's, 1985, creative tasks). Moreover, propositional reasoning tasks do not measure procedural knowledge and are in this way too narrow (as Keating notes).

It should be clear at this point that the key issue is the nature of the relation between conceptual and procedural knowledge at the formal op- 
erations level. It is only a moderate step forward to have made the distinction and to indicate how to measure each component separately. True advancement in the area of adolescent reasoning would be to determine the nature of this link. While interested parties, including myself, work out this relation, it should be noted that such an endeavor would not even be undertaken if the distinction between forms of knowledge had not been made.

Criticisms $\mathrm{e}, \mathrm{f}$, and $\mathrm{g}$ are really about the same issue: the role of content knowledge at the formal operations level. As researchers in the area of mathematics are beginning to realize (e.g., Hiebert \& LeFevre, 1987), procedures can be learned in a meaningless rote fashion, but generalization of these procedures across contexts does not occur unless a rich conceptual knowledge base is present. With respect to formal operations, consider a specific example of the isolation of variables procedure. A novice and an expert car mechanic are each presented with an engine that will not start. The expert possesses a rich conceptual knowledge base consisting of the information that at least six engine parts could be defective. He also knows that certain parts work in concert. The novice considers only one or two parts as possibly implicated and does not consider their interrelation. Clearly, the expert will employ the isolation of variables technique of testing and replacing parts in a very different manner than the novice because of differences in conceptual knowledge. Piaget (1972b) made the point that it is possible to be formal operational only in one's area of expertise. I endorse this point of view, as indicated by my discussion of form and content in my earlier paper. I think, however, Piaget is fundamentally wrong when he says form is independent of content at the formal operations level. In contrast, I think it is more correct to say that hypothetical reasoning (i.e., reasoning about content which the subject knows is false, or may only be possibly true) is possible because propositions are the content of formal operations thought. Propositions can be about anything the subject chooses. When Piaget says that an adolescent reasons like a scientist, he must surely mean they reason hypothetically, not that they reason about no content (i.e., contentless formalisms).

Regarding criticism $h$, Keating makes the point that subjects who comprehend implication should respond "can't tell" to the arguments Denial of Antecedent and Affirmation of Consequent, and "no" to the Modus Tollens argument. In fact, as he notes, 39\% of the older subjects in Byrnes and Overton (1986) incorrectly responded "can't tell" to Modus Tollens. Keating regards this finding as indicating an overgeneralization of this response due to a familiarity with logic language. What is not published in this paper, however, is the analysis of subjects' comments regarding their answers. Only the older subjects (and adults in later studies) respond 
"can't tell" to syllogism: "If it rains, then the grass gets wet. The grass is dry; has it rained?" Here, subjects asked the experimenter: "How long ago did it rain? The grass could be dry by now." Since the experimenter did not give any further information due to a concern for standardization, the subjects responded "can't tell." This response does not reflect an overgeneralization but, rather, a recognition that Modus Tollens applies in some cases but not others. Here, they failed to accept the entailment relation between the antecedent and consequent; i.e., they would not accept that the case "It rained and the grass is dry" is impossible. It is in cases like these where it is uninformative to say that subjects need to be simply familiar with the content to do well. Rather, the content must be familiar and organized in a form which reflects implication, etc. (see my earlier paper regarding organization and negation).

Regarding Keating's last criticism that my model is a decontextualized mirage of mind, it can simply be said that any formalized model, by definition, is decontextualized. It seeks to describe a formal similarity among individual cognitions such as inferences that have the form of Modus Ponens. As Piaget (1970) remarks, structuralism is a method which seeks to summarize across a variety of discrete behaviors using formalisms. One cannot take this formalism abstracted from mind, subject it to tests as a mathematician or logician would, and expect it to function as the mind does. The theorist's model should aim toward descriptive and explanatory adequacy regarding the working of the mind (Chomsky, 1965, pp. 33-47), not toward passing a mathematician's test of internal consistency. Godel, Church, and others have shown how models can be defective in a mathematical sense (e.g., generating contradictory formuli). I think this finding is irrelevant to psychological description and explanation. The primary reason for (1) retaining the parts of the formal operations model that I describe and (2) modifying the model concerning the relation between conceptual and procedural knowledge, is because it is important to strive for descriptive and explanatory adequacy in regard to adolescent thinking. Hence, abandoning entirely all the aspects of the formal operations model as Keating, information processors, and functionalist seem to desire is like throwing the baby out with the bathwater. Such a move would be much more regressive than retaining parts of the model and modifying the remainder to better explain the data.

\section{REFERENCES}

Anderson, J. R. (1976). Acquisition of cognitive skill. Psychological Review, 89, 369-406. Apostel, L. (1967). Syntaxe, semantique et pragmatique. In Logique et connaissance scientifique (Vol. XXII, Encyclopedie de la Pleiade, volume publie sous la direction de Jean Piaget, pp. 290-311). Paris: Gallimard.

Byrnes, J. P. (1988). Formal operations: A systematic reformulation. Developmental Review, 8, 1-22. 
Byrnes, J. P., \& Overton, W. F. (1986). Reasoning about certainty and uncertainty in concrete, causal and propositional contexts. Developmental Psychology, 22, 793-799.

Carcy, S. (1985). Conceptual change in childhood. Cambridge, MA: MIT Press.

Chi, M. T. H., Glaser, R., \& Rees, E. (1982). Expertise in problem solving. In R. Sternberg (Ed.), Advances in the psychology of human intelligence (Vol. I, pp. 7-75). Hillsdale, NJ: Erlbaum.

Chomsky, N. (1965). Aspects of the theory of syntax. Cambridge, MA: MIT Press.

Faulconer, J. E., \& Williams, R. N. (1985). Temporality in human action: An alternative to Positivism and Historicism. American Psychologist, 40, 1179-1188.

Hiebert, J., \& LeFevre, P. (1987). Conceptual and procedural knowledge in mathematics: An introductory analysis. In J. Hiebert (Ed.), Conceptual and procedural knowledge: The case of mathematics (pp. 1-27). Hillsdale, NJ: Erlbaum.

Inhelder, B., \& Piaget, J. (1958). The growth of logical thinking from childhood to adolescence. New York: Basic Books.

Keating, D. P. (1988). Byrnes' reformulation of Piaget's formal operations: Is what's left what's right? Developmental Review, 8, 376-384.

Ladriere, J. (1967). Les limites de la formalisation. In Logique et connaissance scientifique (Vol. XXII, Encyclopedie de la Pleiade, volume publie sous la direction de Jean Piaget, pp. 312-333). Paris: Gallimard.

Lakatos, I. (1971). Falsification and the methodology of scientific research programmes. In I. Lakatos \& A. Musgrave (Eds.), Criticism and the growth of knowledge (pp. 91-180). Cambridge, MA: Cambridge Univ. Press.

Mandler, J. M. (1983). Representation. In P. Mussen (Ed.), Handbook of child psychology (Vol. III, pp. 420-494). New York: Wiley.

Montangero, J. (1985). The evolution of an evolutionary theory of knowledge: In J. Montangero (Ed.), Genetic epistemology: Yesterday and today. New York: City Univ. of New York Press.

Nagel, E., \& Newman, J. R. (1958). Godel's proof. New York: New York Univ. Press.

Piaget, J. (1962). Introduction. In E. W. Beth et al. (Eds.), Implication, formalisation et logique naturelle (Vol. XVI of Etudes d'Epistemologie Genetique, pp. 1-7). Paris: PUF

Piaget, J. (1970). Structuralism. New York: Basic Books.

Piaget, J. (1972a). Essai de logique operatoire: Deuxieme edition du Traite de logique. Paris: Dunod.

Piaget, J. (1972b). Intellectual evolution from adolescence to adulthood. Human Development, 15, 1-12.

Ryle, G. (1971). Knowing how and knowing that. In G. Ryle (Ed.), Collected papers (Vol. II, pp. 212-225). New York: Barnes \& Noble.

Siegler, R. S. (1986). Children's thinking. Englewood Cliffs, NJ: Prentice Hall.

Stone, C. R., \& Day, M. C. (1980). Competence and performance models and the characterization of formal operational skills. Human Development, 23, 323-353.

ReCEIVEd January 26, 1988. 